\title{
Quasi-Static Cyclic Test on a Concrete-Encased Frame-Reinforced Concrete Tube Building Model
}

\author{
Lei Zeng $\mathbb{D}^{1},{ }^{1}$ Yunfeng Xiao, ${ }^{2}$ Juan Chen, ${ }^{1}$ and Yiguang Chen ${ }^{1}$ \\ ${ }^{1}$ School of Urban Construction, Yangtze University, Jingzhou 434023, China \\ ${ }^{2}$ School of Civil Engineering and Mechanics, Huazhong University of Science and Technology, Wuhan 430074, China \\ Correspondence should be addressed to Lei Zeng; zenglei@yangtzeu.edu.cn
}

Received 7 February 2018; Revised 7 May 2018; Accepted 22 May 2018; Published 13 June 2018

Academic Editor: Mohammad A. Hariri-Ardebili

Copyright (c) 2018 Lei Zeng et al. This is an open access article distributed under the Creative Commons Attribution License, which permits unrestricted use, distribution, and reproduction in any medium, provided the original work is properly cited.

\begin{abstract}
This paper experimentally investigated the seismic behavior of a 1:5 reduced-scale model of concrete-encased steel frame-reinforced concrete core tube building. The quasi-static testing with multipoint loading was carried out, and mode-superposition response spectrum method was adopted to control the amplitude of displacement. The damage process, crack pattern, and failure mode were observed. Various parameters were obtained, including lateral deformation, hysteretic characteristics, strain distribution, ductility, and energy dissipation capacity. The test revealed the distributions of base shear between the core tube and frame. The result indicated that the core tube bears major loading and exhibited overturning failure, afterwards frame carry the surplus load and exhibited column tensile failure and joint panel shear failure. The characteristic of two seismic resistant systems are reflected by the excellent cooperation of core tube and frame.
\end{abstract}

\section{Introduction}

Concrete-encased steel frame-reinforced concrete core tube (CS frame-RC core tube) buildings are becoming increasingly popular around the world in high-rise buildings [1-3]. This composite structural system consists of columns located on the periphery of the building and tube located on the center of the building. This arrangement embodies the design concept of two lines to resist shear force $[4,5]$. The first line of defense is RC core tube with high lateral stiffness; it will bear most of the shear force caused by the horizontal earthquake. The second is CS frame, which mainly undertakes the vertical load and partial overturning moment caused by horizontal load. Meanwhile, when the stiffness and resistance of core tube degenerate under a strong earthquake, the framework will continue to bear the surplus loading. Compared with $\mathrm{RC}$ frame structure, the bearing capacity of this composite structural system is obviously improved, and the lateral deformation of the building can be limited to an expected level.

As a distinctive component in this composite structural system, the CS member has been systematically studied. Li et al. [6] have conducted experiment for limit values of axial compression ratio for CS column. Chen et al. [7] explores an analytical model to predict the compressive bearing capacity. The core concrete is enhanced by the steel, which results in the higher bearing capacity. Meanwhile, the steel skeleton can improve the ductility $[8,9]$. Thus, CS member is suitable for the frame of composite structural system. CS frame is proved to have the advantages of reducing cross-section area and excellent global stability [10]. In particular, the exterior joints with unsymmetrical section (T- and L-shaped steel section) can satisfy the nonuniform force state and save space [11, 12]. The failure mechanism of the frame is the beam-hinged mechanism, which satisfies the seismic design principle of strong column and weak beam. The ductility and energy dissipation capacity of CS frame are much better than RC frame [13]. The reinforced concrete core tube provides high initial stiffness and bears major shear. The deformation would be strictly controlled, and lateral instability is effectively prevented [14]. The CS frame-RC core tube buildings benefit from the two components with individual characteristics [15].

There are only a limited number of researches about experiment on the composite structural system. Several shaking table tests were carried out and seismic performance was analyzed [16-18]. The results showed that the whole specimen 
generally exhibited bending failure. The damage mainly occurred at the bottom of core tube and joint. The lateral displacement was still under the safety limits regulated by Chinese Code. As an alternative, numerical simulation methods were also proposed. Some macroelement based models were established for seismic analysis of composite high-rise buildings aiming at predicting their global responses under earthquakes [19-22]. Static pushover analysis, dynamic time history analysis, and incremental dynamic analysis (IDA) method were applied to evaluate the nonlinear responses of composite high-rise buildings [23, 24].

However the test models above are designed with small similarity ratio $(1 / 20,1 / 35)$ [16-18], which is restricted by the shaking table capacities. The disparity between the acceleration similarity ratio of earthquake actions and actual similarity ratio for gravity acceleration cannot be ignored [25]. In addition, lateral force caused by earthquake is expected to resist by both frame and core tube through composite action. Because there are remarkable differences in stiffness between frame and core tube $[23,24,26]$, the frame columns may fail by shear and crush in resisting strong earthquakes and eventually leads to sudden collapse of whole structure [27, 28]. It is significant to evaluate the seismic performance of this composite structural system through specimen with a larger similarity ratio, which can represent the general behavior of the prototype. Mechanical behavior of the parts (the bottom of core tube and joint of frame) under complicated force state should be carefully analyzed.

In this paper, a 1:5 reduced-scale model of concreteencased steel frame-reinforced concrete core tube building is constructed, and quasi-static testing is conducted to assess the response under axial compression and cyclic horizontal load. The lateral load and corresponding displacement and strain of steel and concrete are measured. The crack pattern and failure mode of each component are observed. The seismic performance is evaluated by the obtained hysteretic curve, ductility, energy dissipation capacity, and stiffness degradation. The function of two seismic resistant systems of this structure is verified.

\section{Experimental Program}

2.1. Test Model Design. A typical multistory CS frame-RC core tube building prototype was designed in accordance with the Code for Seismic Design of Buildings of China (GB500232009). The effects of vertical loads (live- and dead-loads) and lateral loads were provided referring to the Technical Specification for Concrete Structures of Tall Building (JGJ32002). The prototype building was designed based on an 8degree seismic fortification intensity zone and a II-type of site classification. The design basic acceleration of ground motion $a_{\mathrm{g}}$ was $0.20 \mathrm{~g}$, which was with a reference probability of exceedance, $10 \%$ in 50 years. The site was classified according to the equivalent shear-wave velocity of soil and the site overlying depth, the design characteristic period of ground motion $T_{\mathrm{g}}$ was $0.35 \mathrm{~s}$ for a II-type of site. It should be noted that the seismic intensity and response spectrum used during the design were those given in the Chinese seismic code.
TABLE 1: Similarity relationship of the model.

\begin{tabular}{lcc}
\hline Physical quantity & Dimensions & Ratio of similitude \\
\hline Length & $\mathrm{L}$ & $S_{\mathrm{L}}=1 / 5$ \\
Young's modulus & $\mathrm{FL}^{-2}$ & $S_{\mathrm{E}}=1$ \\
Mass & $\mathrm{FT}^{2} \mathrm{~L}^{-1}$ & $S_{\mathrm{m}}=1 / 25$ \\
Stress & $\mathrm{FL}^{-2}$ & $S_{\sigma}=1$ \\
Time & $\mathrm{T}$ & $S_{\mathrm{T}}=$ \\
Poisson ratio & 1 & $\nu=1$ \\
Force & $\mathrm{F}$ & $S_{\mathrm{F}}=1 / 25$ \\
\hline
\end{tabular}

The frame is composed of CS columns and steel beams with I cross-section, while the core tube is made of reinforced concrete. Considering the laboratory conditions, a 1:5 reduced-scale model was constructed for the quasi-static tests. The model was 10 stories with square cross-sections, with 20 beams and 12 columns in each story. The total height of the model was $8700 \mathrm{~mm}$. The depth of the foundation, the first story, and the rest of the stories were $500 \mathrm{~mm}, 1000$ $\mathrm{mm}$, and $800 \mathrm{~mm}$, respectively. Two holes were arranged on each story for elevator doors. The details and dimensions of the specimen are shown in Figure 1. It should be mentioned that the selected span is small because of the limitation of laboratory conditions. Compared with typical building, the linear stiffness ratio of beams and floor system increases. The capacity of shear transferring between core tube and frame is enlarged. It may lead to less damage degree of beams and floor system.

Based on the requirements of Architectural Structure Load Standards (GB50009-2001) of China, the live- and deadloads for the test model are $2.0 \mathrm{kN} / \mathrm{m}^{2}$ and $1.6 \mathrm{kN} / \mathrm{m}^{2}$, respectively. A certain amount of sandbags is stacked on floors to simulate the uniform load. Because it is difficult and dangerous in construction, only the tenth-floor slab is not constructed. But the columns, beams, and core tube are still constructed, and the ninth-floor slab is defined as the top of specimen. The removed dead load is added by the additional sandbags in the ninth floor. The materials used for the test model were identical to those of the prototype structure, thereby indicating that the scaling factor of the elastic modulus was $S_{\mathrm{E}}=1$. Table 1 shows the similarity relationships.

2.2. Test Model Construction. The CS columns had a square cross-section of $100 \mathrm{~mm} \times 100 \mathrm{~mm}$. Figure 2 shows the configurations and skeleton of the CS columns. The cross-shaped structural steel used in the columns consisted of several hotrolled steel plates. The steel plates were welded to create a cross-shaped steel section. Figure 3 shows the steel beams and configurations of beam-column joints. An I cross-section was adopted in the steel beams. The beams steel plates were welded to the columns steel skeleton.

The composite slab was adopted. The slab system was composed of thin steel plate, concrete, steel bar, and stud connectors. Single-layer mesh reinforcement is used, and 10 $\mathrm{mm}$ length stud connectors were welded to the steel plate to strengthen the bond between the steel plate and concrete. A 
North

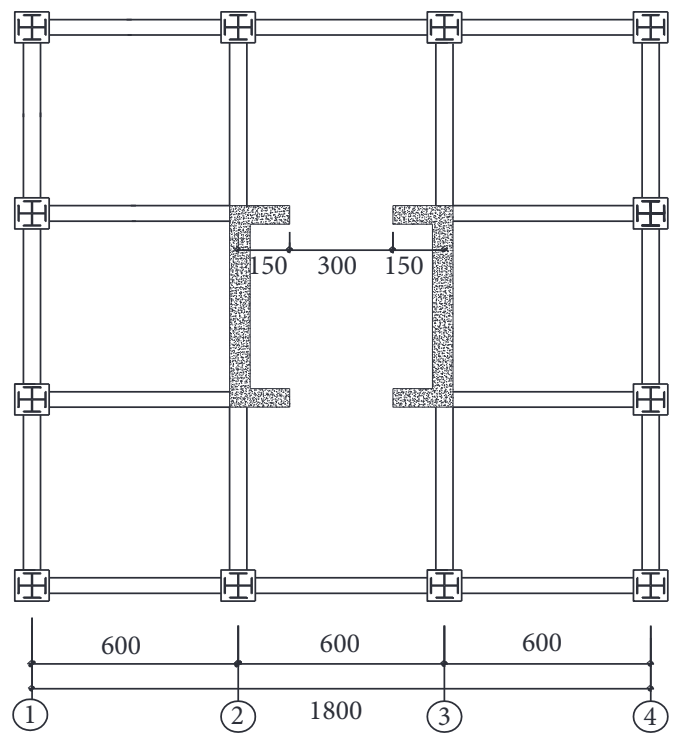

(a) Cross-section

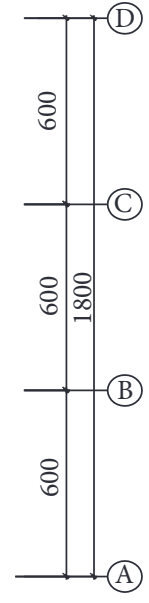

(A)

(b) Elevation

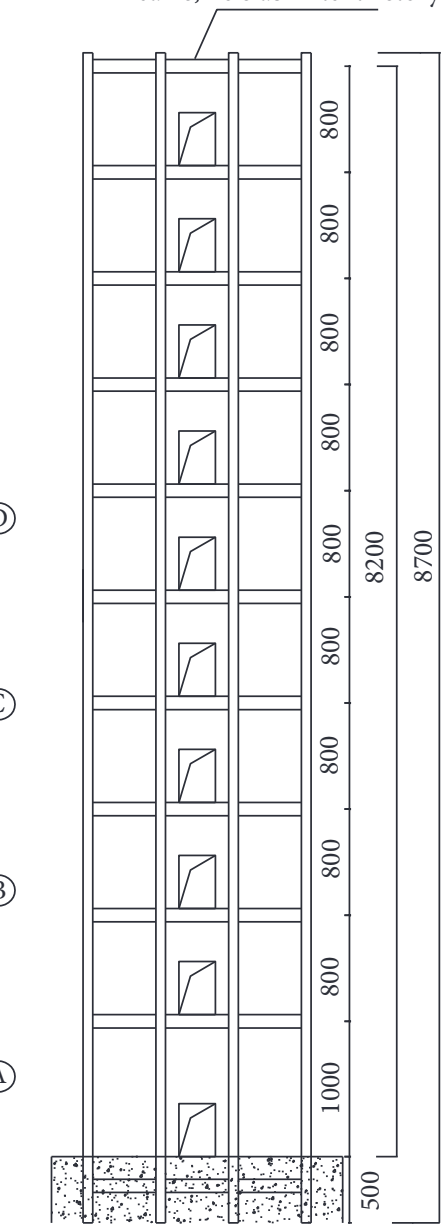

Beams, no slab in tenth story

FIGURE 1: Dimensions of specimen (units: mm).
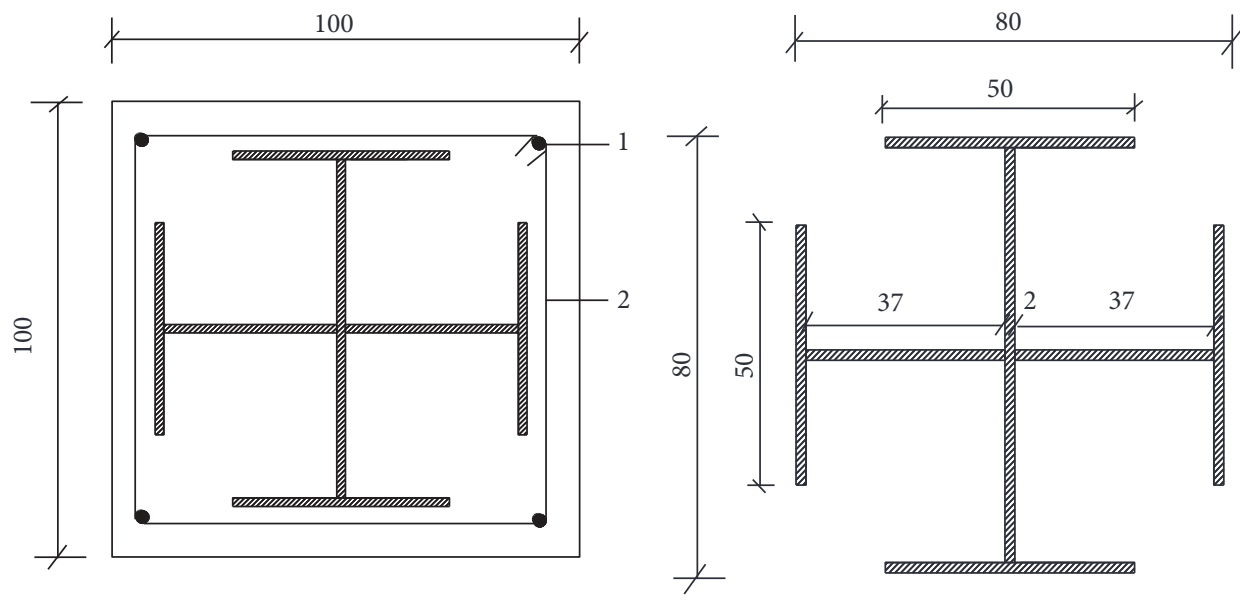

1: Longitudinal bars $\phi 4$

2: Stirrups $\phi 4 @ 100$

(a) Column

(b) Steel skeleton

FIGURE 2: Configurations and skeleton of CS columns (units: $\mathrm{mm}$ ). 


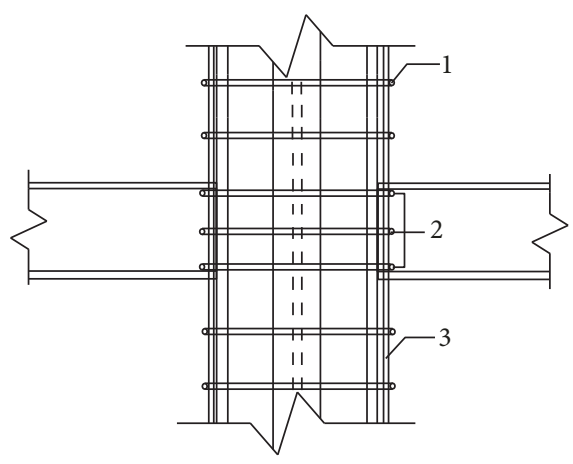

1: Stirrups $\phi 4 @ 100$

2: Stirrups $\phi 4 @ 50$

3: Longitudinal bars $\phi 4$

(a) Joint

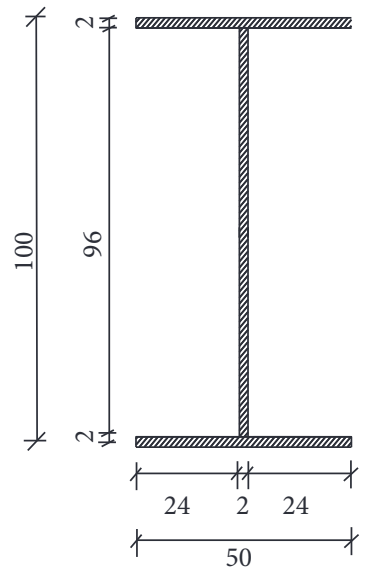

(b) Beam

FIGURE 3: Details of joint and beam (units: $\mathrm{mm}$ ).

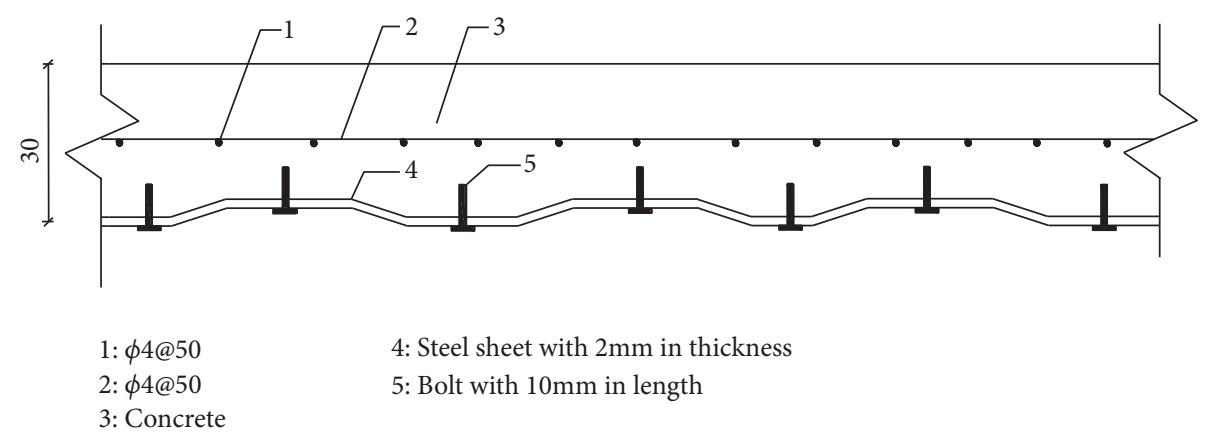

FIgURE 4: Composite slab system (units: mm).

TABLE 2: Materials properties of steel.

\begin{tabular}{lccc}
\hline Material & $\begin{array}{c}\text { Yield Strength } \\
f_{\mathrm{y}}\left(\mathrm{N} / \mathrm{mm}^{2}\right)\end{array}$ & $\begin{array}{c}\text { Ultimate Strength } \\
f_{\mathrm{u}}\left(\mathrm{N} / \mathrm{mm}^{2}\right)\end{array}$ & $\begin{array}{c}\text { Elastic Modulus } \\
E_{\mathrm{s}}\left(\mathrm{N} / \mathrm{mm}^{2}\right)\end{array}$ \\
\hline$\Phi 4$ bars & 305 & 424 & $2.1 \times 10^{5}$ \\
$\Phi 12$ bars & 347 & 451 & $2.1 \times 10^{5}$ \\
Steel plate & 327 & 463 & $2.0 \times 10^{5}$ \\
\hline
\end{tabular}

sectional view and details of the reinforcements are shown in Figure 4.

A square cross-section is used for the core tube, and the dimensions are shown in Figure 5. The thickness is $60 \mathrm{~mm}$ for the first two floors and $40 \mathrm{~mm}$ for the rest. Doublelayer mesh reinforcing is arranged in the tube, including four $12 \mathrm{~mm}$ diameter bars in the corners. For the actual structure, the cross-section indeed decreases along with the height. As the scale of specimen is reduced by similarity ratio, there is a small difference in dimension. For the convenience of construction, the using cross-section is identical.

2.3. Material Properties. The material properties of the steel plate and reinforcement were tested as shown in Table 2. The spot mixed concrete was used for the CS columns, composite slabs, and core tube. The measured cube compressive strength $\left(f_{\mathrm{cu}}\right)$ before test was $41.5 \mathrm{~N} / \mathrm{mm}^{2}$.
2.4. Test Setup and Loading Histories. The structural vibration induced by earthquakes is contributed by all modal responses. The mode-superposition response spectrum method is an effective and accurate method, which can consider the influence of higher mode shapes [29]. The contribution of each mode shape is different in the total response; thus the participation coefficient $\eta$ is introduced to describe this proportion. The loading program is detailed as follows.

(1) Reference [5] has carefully described the program about measuring dynamic characteristics. Several vibration pickup sensors were installed as shown in Figure 6(a). A signal acquisition system with at most six channels was connected to record the data; however it was enough for measuring the mode shapes. The details of vibration pickup sensors and acquisition process are shown in Figure 7. 


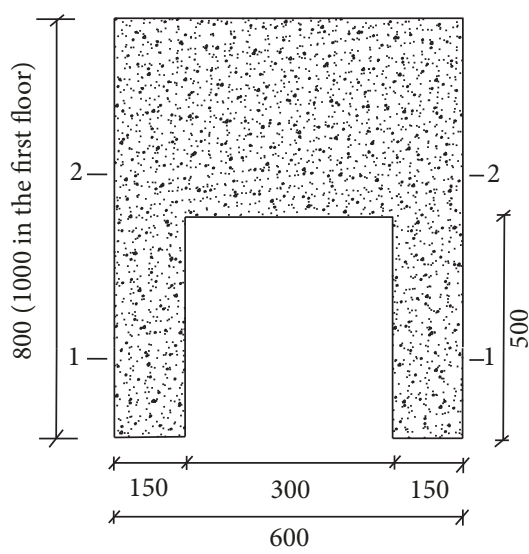

(a) Dimension of the north and south wall

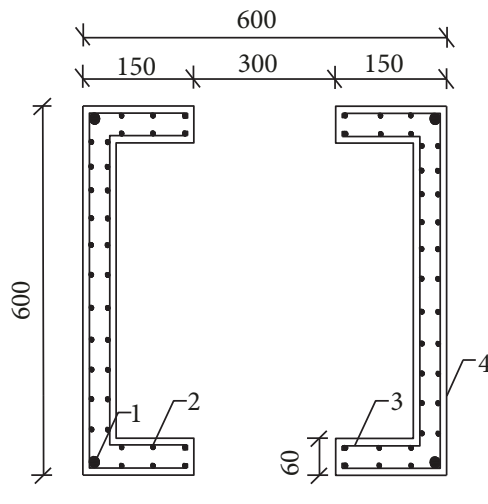

1: $\phi 12 \quad 3: \phi 4 @ 50$

2: $\phi 4 @ 50 \quad 4:$ Concrete

(c) Reinforcement of section 1-1

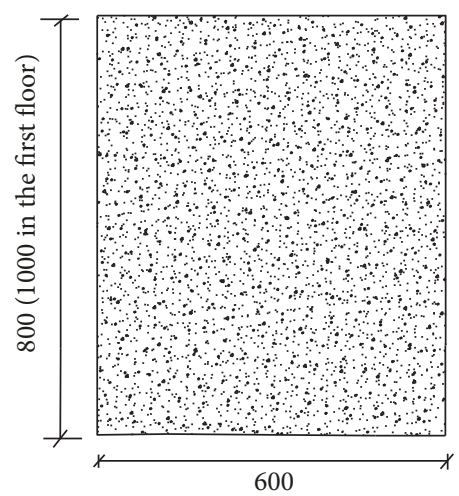

(b) Dimension of the east and west wall

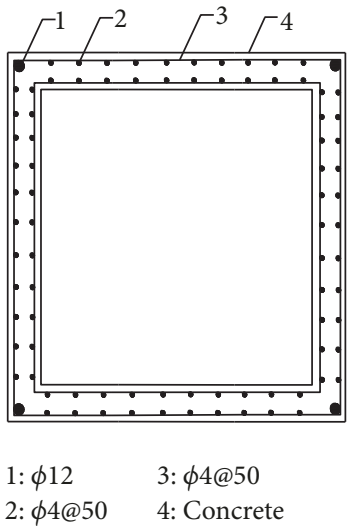

(d) Reinforcement of section 2-2

FIGURE 5: Detail of core tube (units: mm).

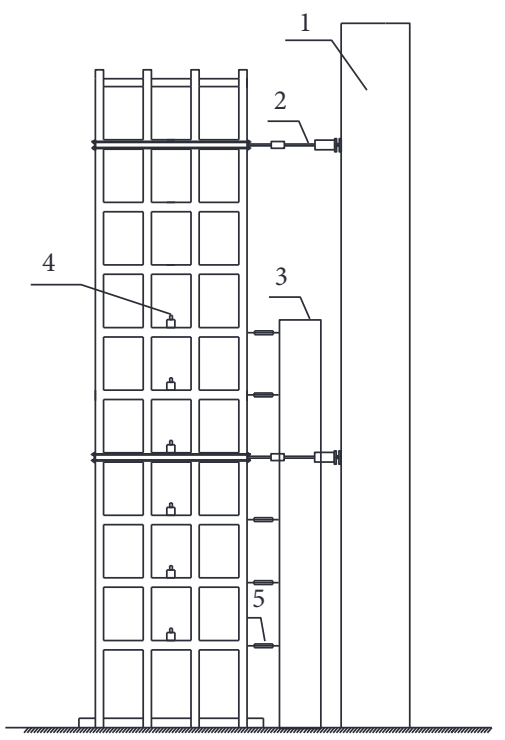

1: Reaction wall 4: Vibration pickup sensor

2: Actuator

3: Scaffold

(a) Loading and measuring device

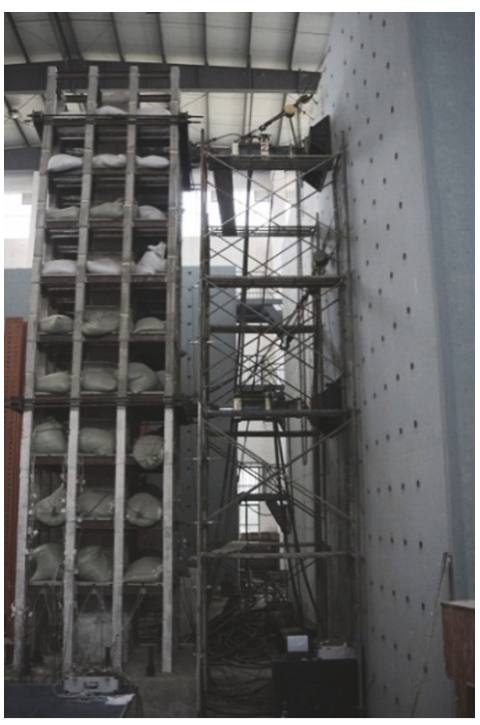

(b) Picture of specimen

FIgURE 6: The test setup. 
TABLE 3: Participation coefficients of mode shapes.

\begin{tabular}{lccccc}
\hline Mode shape & 1st-order & 2nd-order & 3rd-order & 4th-order & 5th-order \\
\hline Participation coefficient $\eta_{i} / \%$ & 74.41 & 14.26 & 5.50 & 2.82 & 1.49 \\
\hline
\end{tabular}

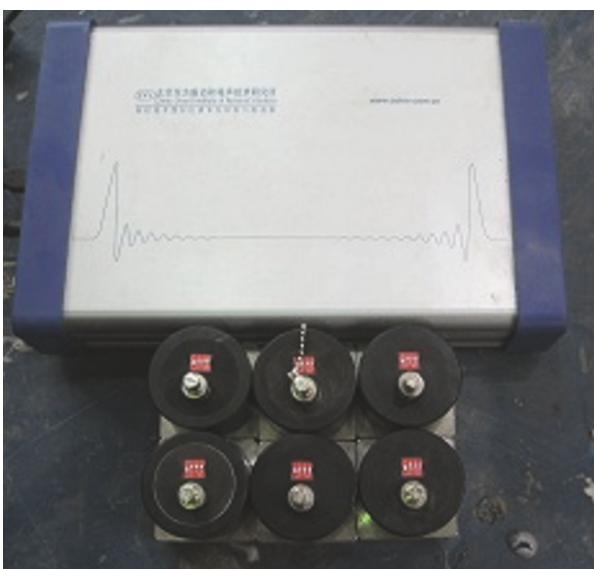

(a) Vibration pickup sensors and DASP system

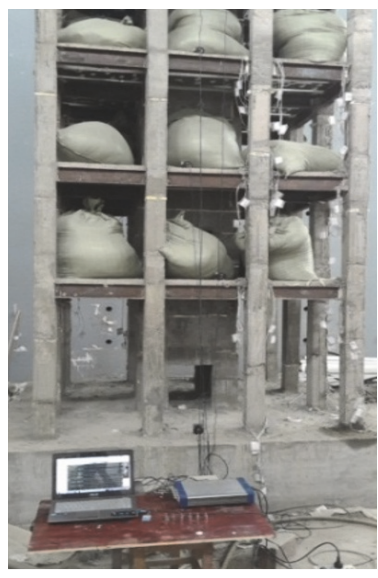

(b) Measuring process

FIGURE 7: Measurement for dynamic characteristics.
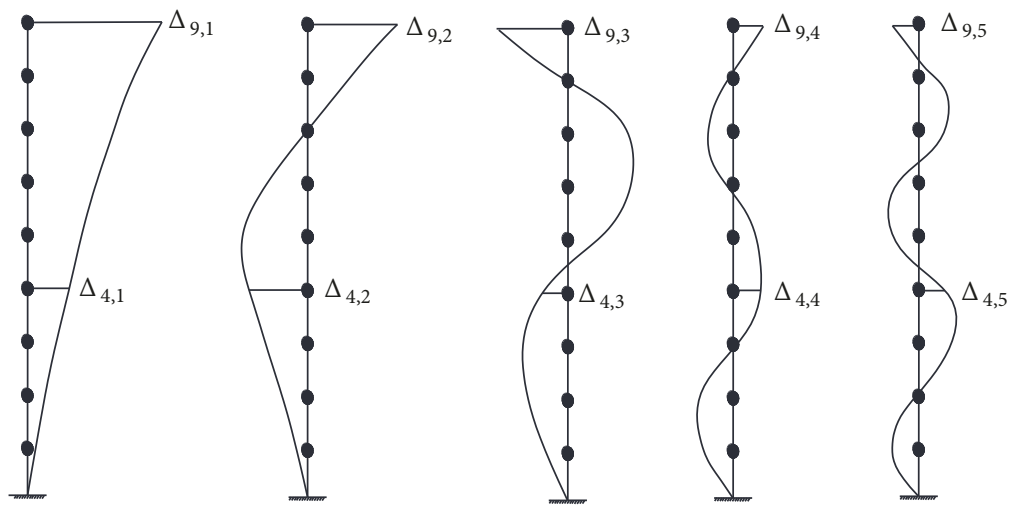

FIgURE 8: The first five mode shapes.

(2) Based on the dynamic characteristics, Data Acquisition and Signal Processing (DASP) program was adopted to carry out the modal analysis (see Figure 7(b)). The higher mode shapes and corresponding participation coefficient $\eta$ were obtained. According to Code for Seismic Design of Buildings (GB 50011-2010), the number of selected mode shapes is determined by the sum of $\eta$, which should be more than $90 \%$. Table 3 shows the $\eta$ of first five modes; the sum has already satisfied the requirement. The density of used material should be enlarged to five times based on the scale effect. However the steel and concrete material with 5fold density are not available, and the mass missing is not considered. But the required live- and dead-loads are taken into account and calculated by scale factors. This part of mass (including the mass of removed 10th-floor slabs) is applied by sandbags. The missing mass due to scaled material density leads to the decrease of effective floor masses and total mass. The mode shapes and participation coefficients are influenced.

(3) The reverse cyclic loading applied by multipoint is proved to accurately consider the influence of higher mode shapes [19]. According to existing experimental equipment, two actuators were set up at the 4th- and 9th-floor slabs (see Figure 6). The displacement-controlled method was adopted, and Figure 8 shows the first five mode shapes. The amplitude of displacement is defined by (1) [29] and finally $\Delta_{9} / \Delta_{4}=1.5: 1$. In the loading program, displacement increment at 9th floor is $8 \mathrm{~mm}$ per level, and three cycles are applied at each level as shown in Figure 9. Once the bearing capacity falls to $85 \%$ of the ultimate lateral load, or the specimen is unable to continue bearing axial forces, the test is regarded as finished.

$$
\frac{\Delta_{9}}{\Delta_{4}}=\frac{\sum_{i=1}^{N} \eta_{i} \Delta_{9, i}}{\sum_{i=1}^{N} \eta_{i} \Delta_{4, i}} \quad i=1,2,3,4,5
$$




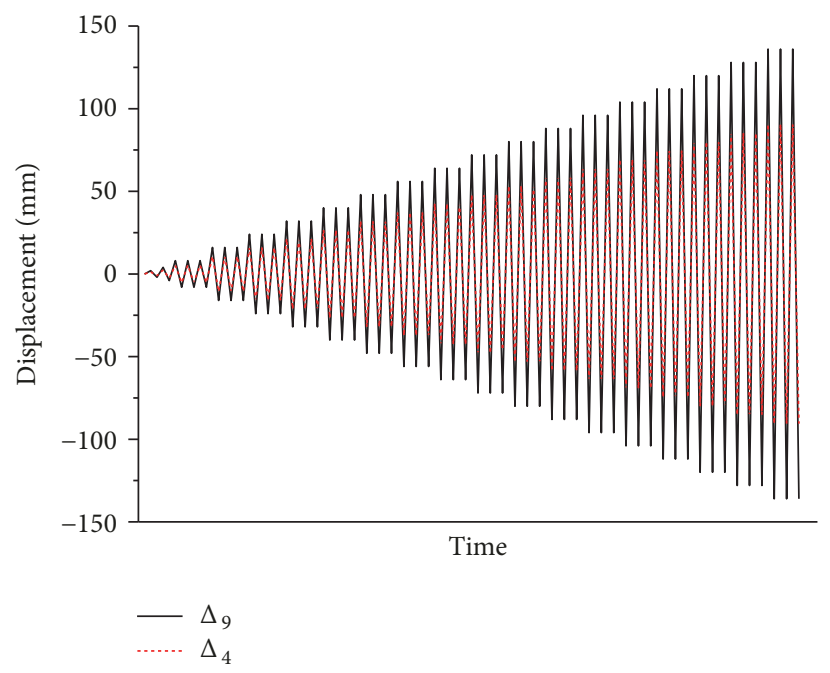

FIGURE 9: The history of loading program.

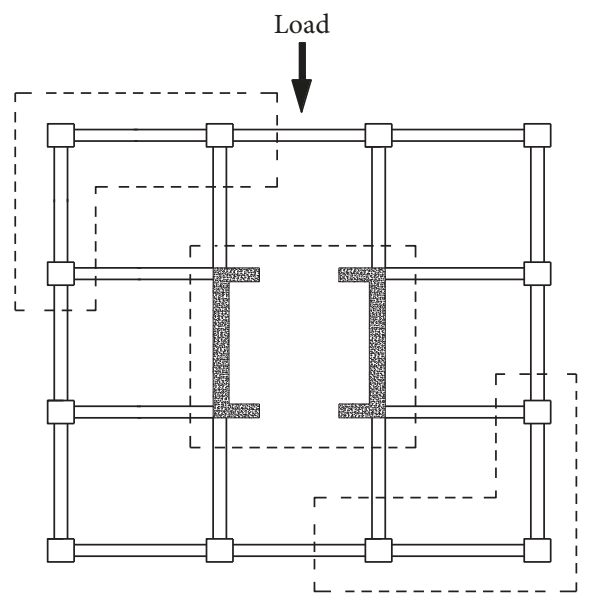

(a) The selected component for attachment of strain gauges

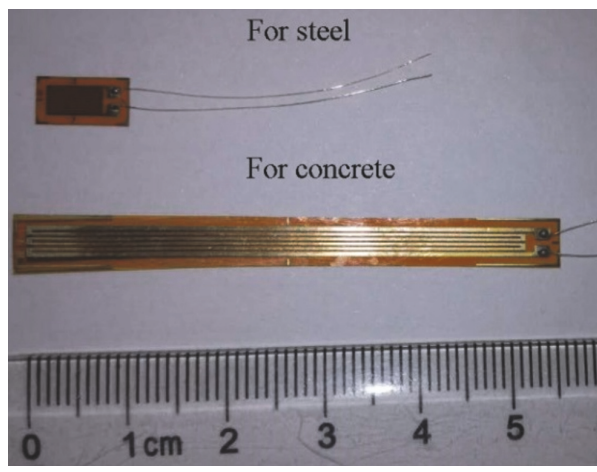

(b) Strain gauges for concrete and steel

FIGURE 10: The arrangement of strain gauges.

where $\Delta_{9}$ and $\Delta_{4}$ are the actual displacement applied on 9th and 4th floor; $\Delta_{9, i}$ and $\Delta_{4, i}$ are lateral displacement of $i$-th mode shape as shown in Figure $8 ; \eta_{i}$ is participation coefficients of $i$-th mode shapes.

2.5. Instrumentation. The measuring points were defined to capture the overall response of the test model during loading as well as any local effects, such as CS columns and core tube yielding. Displacement sensors were mounted on the slabs of each story at the loading side. Due to the symmetry of cross-section, the components at 1st and 2nd floor in Figure 10(a) were selected for attaching strain gauges as shown in Figure 10(b), and the detail is shown in Figure 11.

\section{Experimental Results}

3.1. Experimental Phenomena. Figures $12-15$ show the development of crack pattern. In the initial stage, the specimen exhibited elastic state after loading and unloading. As the top displacement reached $16 \mathrm{~mm}$, horizontal cracks primarily occurred at the boundaries along the wall height, and microcracks developed at the bottom of column on the first floor. Then the cracks gradually extended with opening and closing. When the top displacement reached $32 \mathrm{~mm}$, diagonal cracks with $45^{\circ}$ angle were observed on the west and east of core tube on the first floor. As the top displacement reached $56 \mathrm{~mm}$, shear cracks appeared in column-beam joints, and local bulge occurred on the profiled steel sheets on 4th, 7th, 8th, and 9th floors. The diagonal cracks on the core tube eventually developed to X-shaped intersecting cracks. Once top displacement reached $88 \mathrm{~mm}$, concrete at wall edges seriously spalled and crushed. The longitudinal reinforcements were exposed, which were accompanied by the buckling and fracture. At present the core tube was regarded as overturning failure, and the frame continued to bear the surplus loading. Horizontal cracks were found on 


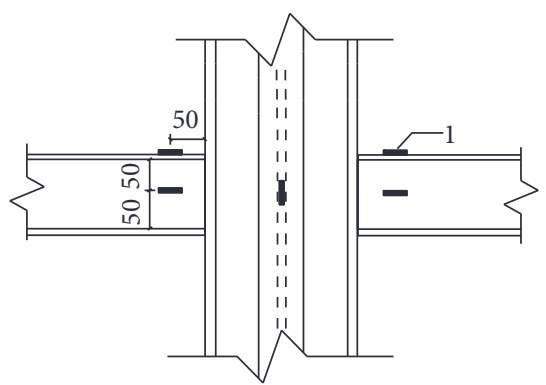

1: Strain gauges

(a) Strain of steel skeleton
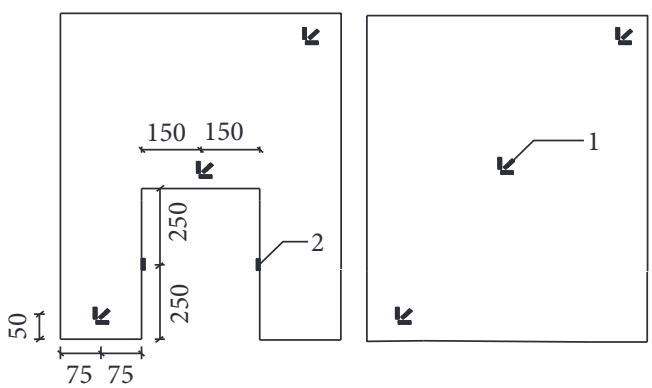

1: Strain rosettes

2: Strain gauges

(b) Strain of concrete

Figure 11: Arrangement of strain gauges and rosettes at the first and second floors (units: $\mathrm{mm}$ ).

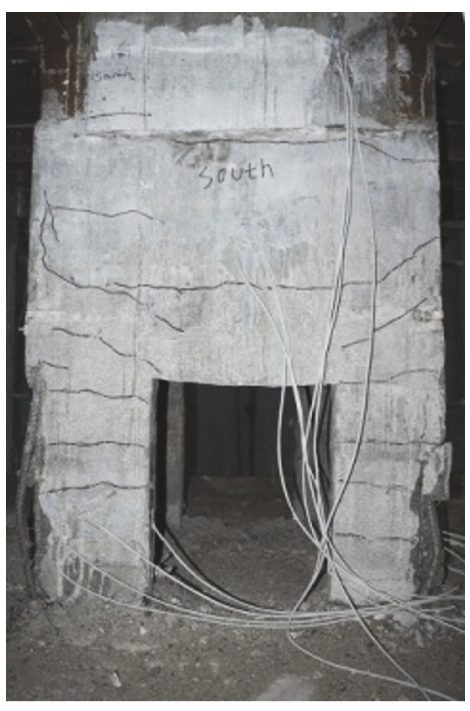

(a) The south wall

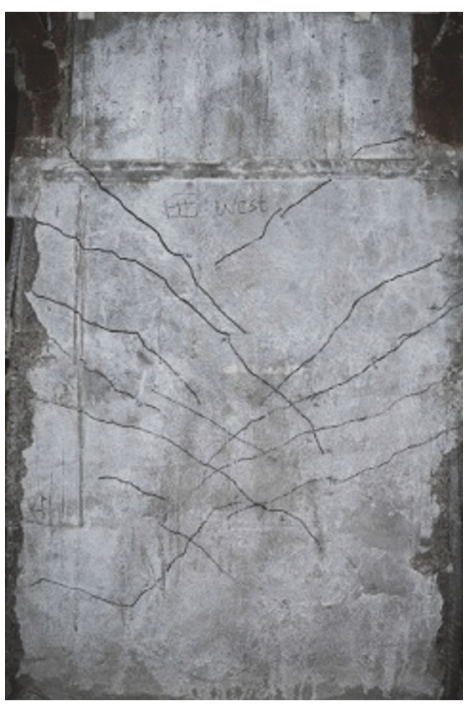

(c) The west wall

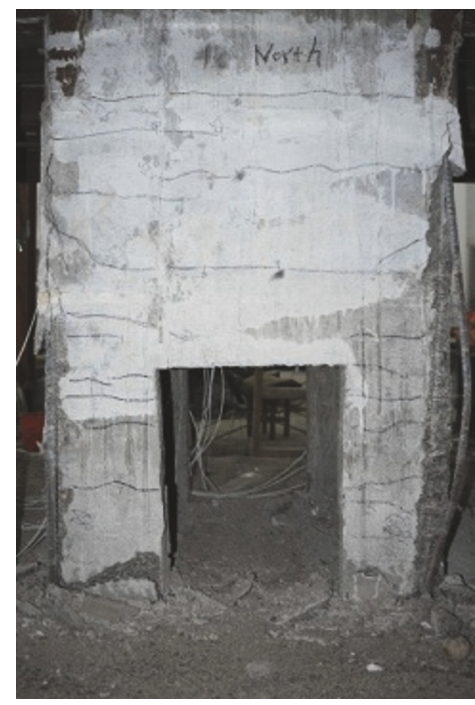

(b) The north wall

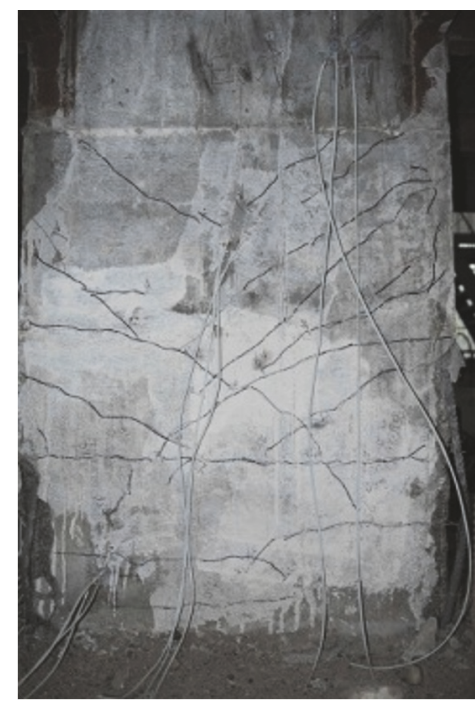

(d) The east wall

Figure 12: Cracks on core tube at the first floor. 


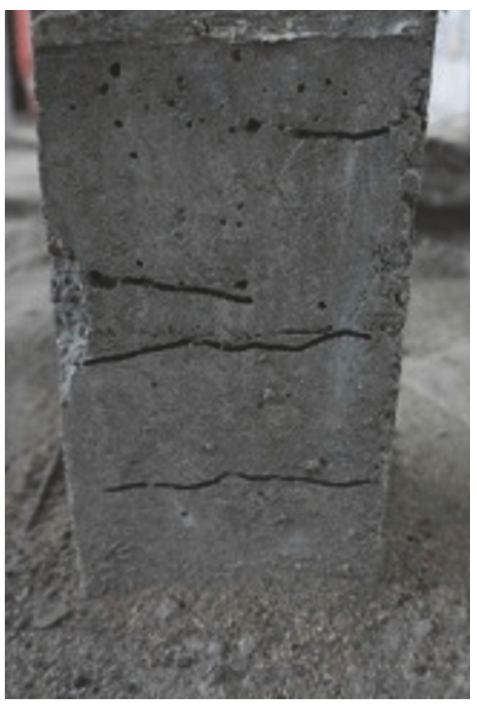

(a) The interior column

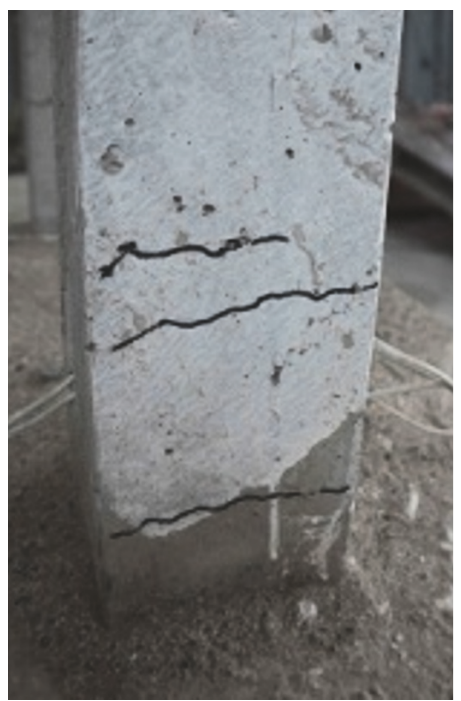

(b) The corner column

Figure 13: Cracks on columns at the first floor.

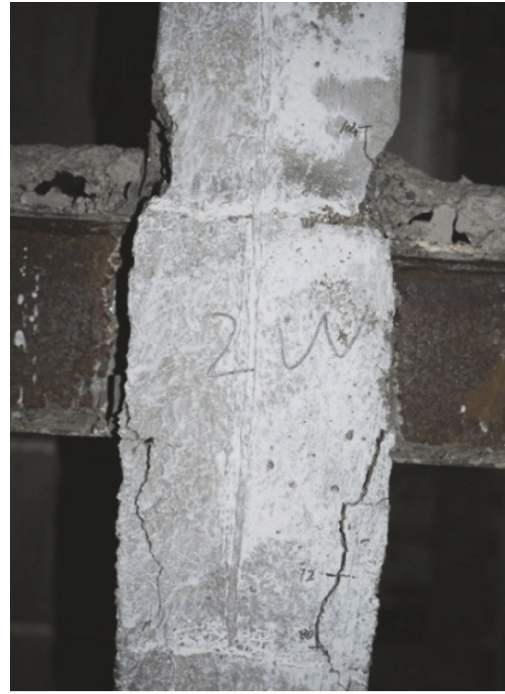

(a) The interior joint

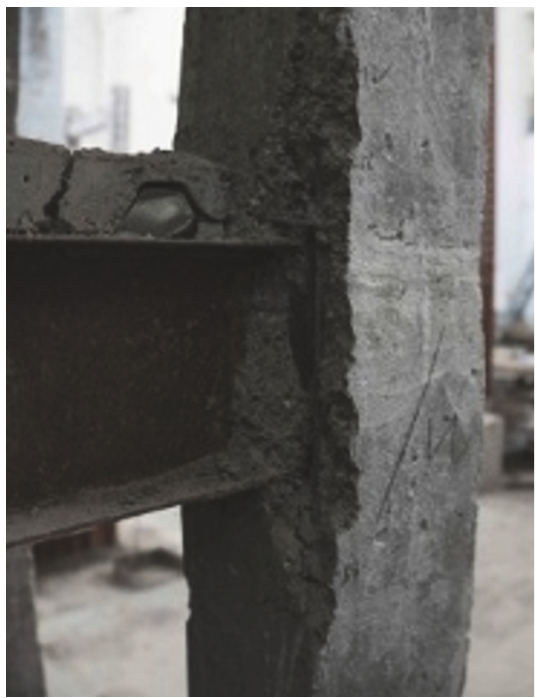

(b) The exterior joint

FIGURE 14: Cracks on joints at the second floor.

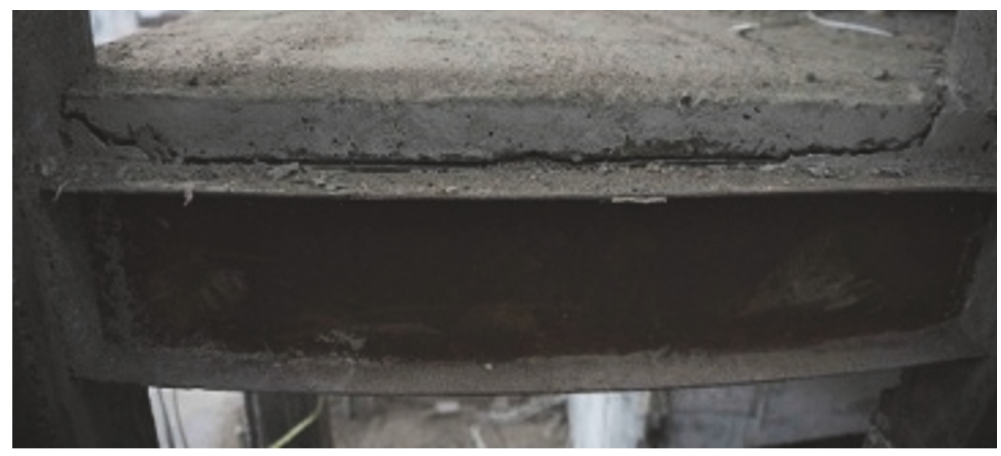

FIGURE 15: Cracks on slab at the second floor. 


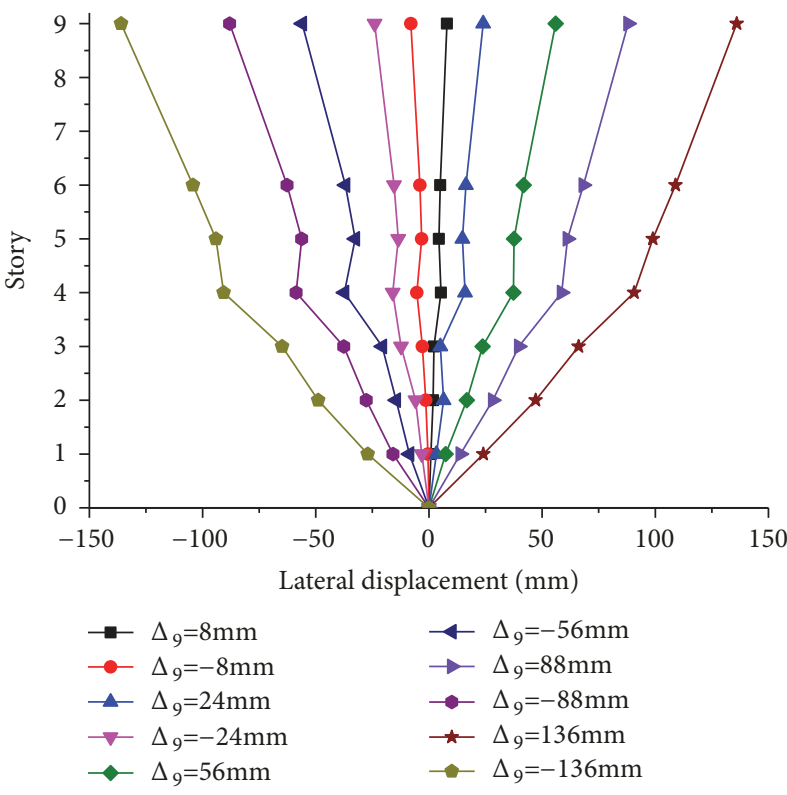

(a) Absolute displacements

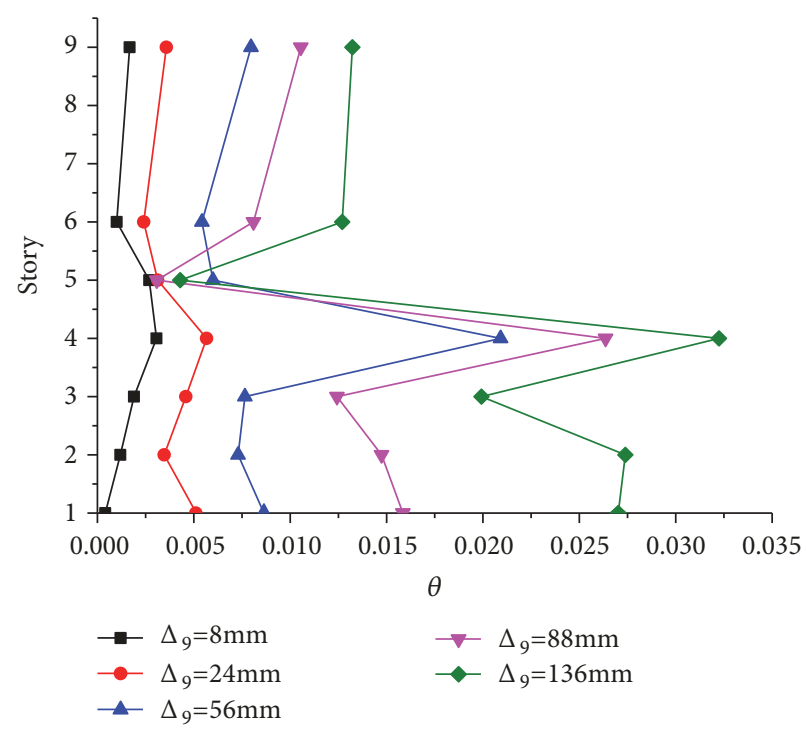

(b) Story drift ratios

FIGURE 16: Lateral deformation.

the surfaces of the 1st- and 2nd-floor slabs, massive spalling of concrete occurred in the joint, and the steel skeleton was deformed. Once the top displacement reached $136 \mathrm{~mm}$, the load reduced to $85 \%$ of the ultimate bearing capacity, the specimen was severely damaged, and experiment was concluded.

Each component of the specimen exhibited various failure modes. The core tube exhibited relatively wide cracks and severe concrete crushing localized at the bottom. There were two types of cracks as shown in Figure 12; one was horizontal tension cracks, which mainly occurred on the north and south of core tube (perpendicular to the loading direction). Under the action of tension and compression, the concrete was seriously crushed, and the width of the cracks was approximately $10 \mathrm{~mm}$ (see Figures 12 (a) and 12(b)). The other was oblique shear cracks, which mainly occurred on the west and east of core tube (parallel to the loading direction). Cracks gradually extended at $45^{\circ}$ angle and eventually formed X-shaped intersecting cracks (see Figures 12(c) and 12(d)).

Compared with the core tube, frame exhibited relatively few cracks as shown in Figures 13 and 14. Horizontal tension cracks occurred at the bottom of the column, with a small amount of concrete spalling. Shear cracks were observed in the joints particularly on the 1st and 2nd floors, which were accompanied by severe concrete crushing. The longitudinal reinforcements and steel skeleton were exposed and bent. As shown in Figure 15, horizontal cracks mainly occurred on the floor slabs. Concrete was crushed at the boundary between floor slabs and the core tube, and the steel plate was compressed and exhibited locally bulging.

In general the core tube characterized by large lateral stiffness had borne major loading and worked as first seismic resistant system. Once it failed by overturning, the frame supported the structure as the second seismic resistant system.
3.2. Deformation and Strains. The lateral displacement of each floor at stages of $\Delta_{9}= \pm 8 \mathrm{~mm}, \pm 24 \mathrm{~mm}, \pm 56 \mathrm{~mm}, \pm 88$ $\mathrm{mm}$, and $\pm 136 \mathrm{~mm}$ is shown in Figure 16. Interstory drift ratio $\theta_{i}$ is defined as follows:

$$
\theta_{i}=\frac{\left(\Delta_{i}-\Delta_{i-1}\right)}{h_{i}} \quad i=1,2,3, \ldots, 9
$$

where $\Delta_{i}$ is lateral displacement of the $i$-th floor and $h_{i}$ is the height of $i$ th floor.

The absolute displacements and story drift ratios are shown in Figure 16. According to (2) and measured data, the maximum story drift ratio is $\theta_{4}$. During the loading process, the damage patterns at 4 th floor presented previously. As the lateral displacement increased, the stiffness at 4 th floor obviously degenerated, and the damage degree was larger than other floors. According to Technical Specification for Concrete Structures of Tall Building (JGJ3-2002) of China, the limiting value of elastic-plastic interstory ratio for framecore tube structure is 0.01 . It is clear that when $\Delta_{9}$ reached 32 $\mathrm{mm}$, the specimen begins to enter the plastic stage.

The strain of steel skeleton in columns is at range of 1974-3148 $\mu \varepsilon$, which gets into the yielding stage. The strain of steel skeleton in beam is generally less than $500 \mu \varepsilon$, and it remains in the elastic stage. The concrete strain is 1284-3539 $\mu \varepsilon$, exceeding the ultimate compressive strain of 0.003 . In general, under the action of cyclic loading, both of the columns and core tube mainly bear lateral loads.

3.3. Hysteretic Curve. The hysteretic curve of the specimen indicates the relationship between base shear and top displacement. The hysteresis curve shape is between the spindle and the " $S$ " form, as shown in Figure 17. The specimen generally exhibited three stages: yielding, ultimate, and failure stage. In the initial stage of loading, the specimen remains 
TABLE 4: Degradation of bearing capacity.

\begin{tabular}{lccccccc}
\hline \multicolumn{2}{l}{ Top displacement $/ \mathrm{mm}$} & 88 & 96 & 104 & 112 & & 120 \\
\hline \multirow{2}{*}{$\lambda_{i} / \%$} & Positive & 1 & 0.97 & 0.98 & 0.98 & 0.96 & 0.96 \\
& Negative & 1 & 0.97 & 0.97 & 0.97 & 0.94 & 0.95 \\
\hline
\end{tabular}

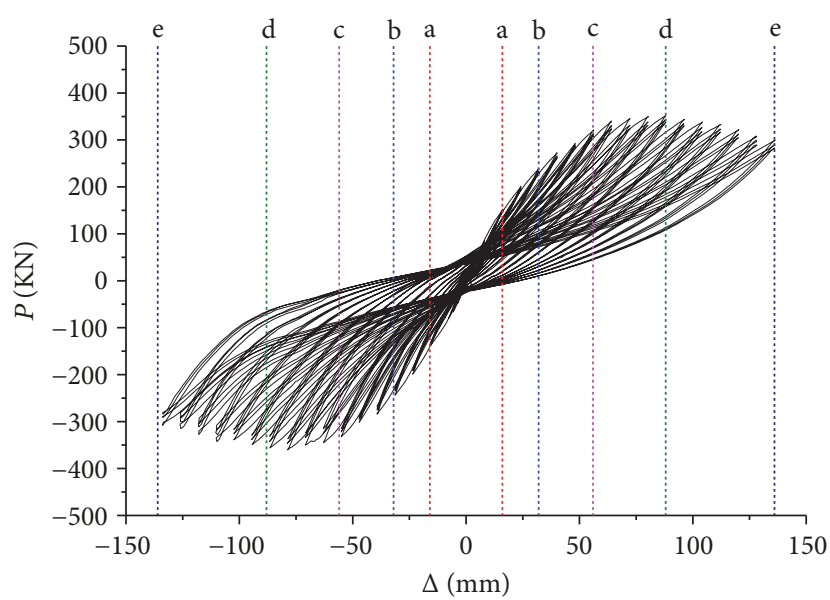

FIgURE 17: Hysteretic curve.

elastic, the loading and unloading curves are straight, and minor residual deformation occurs. With increasing horizontal displacement, the specimen reaches the elastic-plastic stage, and the area of the hysteresis loops increases. The peak loads of the subsequent two cycles, at one displacement level, gradually decline. When top displacement reaches $32 \mathrm{~mm}$, the hysteresis loop inclines toward the horizontal axis, and obvious stiffness degradation and residual deformation indicate that the specimen attains yielding stage. The specimen reaches the ultimate stage at $88 \mathrm{~mm}$, where the maximum load is $356 \mathrm{kN}$. The core tube completely fails at this point, the frames have varying levels of damage, and the bearing capacity of the specimen begins to decrease. As the top displacement reaches $136 \mathrm{~mm}$ the specimen moves into the failure stage.

The damage process of different components can be described as follows (zones a-e as shown in Figure 17): (a) when $\Delta_{9}$ was less than $16 \mathrm{~mm}$, no damage occurred and the specimen was intact. Then minor damage occurred on the columns at first floor. (b) When $\Delta_{9}$ reached $32 \mathrm{~mm}$, the core tube began to get damaged; however the columns did not develop further damage. (c) When $\Delta_{9}$ reached $56 \mathrm{~mm}$, the core tube seriously got damaged; meanwhile the joints and floor slabs slightly got damaged. (d) When $\Delta_{9}$ reached 88 $\mathrm{mm}$, the core tube failed and the damage degree of joints and slabs was aggravated. (e) When $\Delta_{9}$ reached $136 \mathrm{~mm}$, the frame got into failure stage.

According to the Specification of Testing Methods for Earthquake Resistant Building (JGJ101-96) of China, the degradation of bearing capacity can be described by coefficient $\lambda_{i}$ in (3), shown in Table 4.

$$
\lambda_{i}=\frac{P_{i}}{P_{i-1}}
$$

where $P_{i}$ is the peak load at $i$-th displacement level.

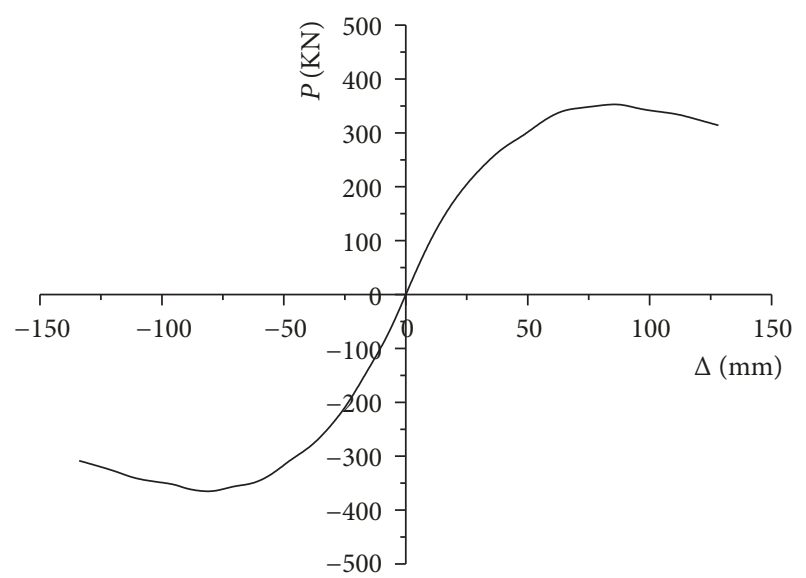

FIGURE 18: Skeleton curve.

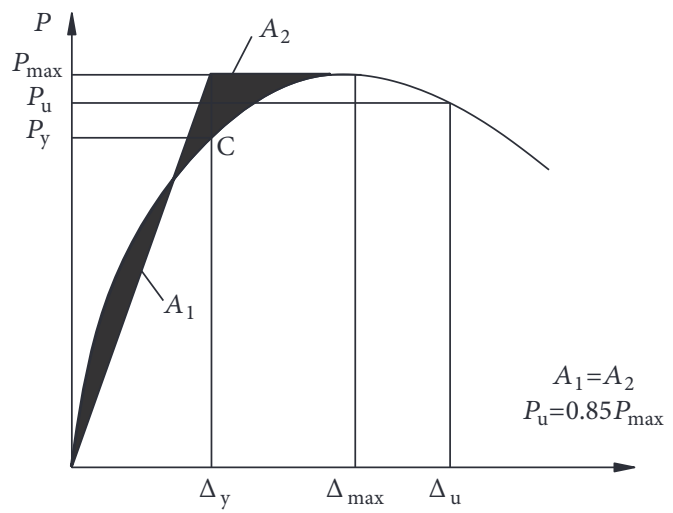

FIGURE 19: Equivalent energy method.

The peak loads of the specimen during the second and third cycles of each displacement level are both lower than the previous ones, and, finally, the bearing capacity degenerates by about $5 \%$.

3.4. Envelope Curve. The skeleton curve of the specimen is symmetrical in both positive and negative directions as shown in Figure 18. In order to confirm the yield and damage points, the equivalent energy method is adopted, as shown in Figure 19. $A_{1}$ and $A_{2}$ are the shaded areas. The loads and displacements at the yield point, limit point, and failure point are presented in Table 5, where $P_{\mathrm{y}}, \Delta_{\mathrm{y}}, P_{\max }, \Delta_{\max }, P_{\mathrm{u}}$, and $\Delta_{\mathrm{u}}$ are the loads and displacements at yielding, ultimate, and failure points, respectively.

The skeleton curve shows the elastic-, plastic-, and degradation-stages. In the initial stage, the curve is a straight line, bearing capacity increases rapidly, and stiffness remains stable. With increasing loads, concrete cracks and steel 
TABLE 5: Yielding, ultimate and failure point of specimen.

\begin{tabular}{lcccccc}
\hline \multirow{2}{*}{ Stage } & \multicolumn{2}{c}{ Yielding } & \multicolumn{2}{c}{ Ultimate } & \multicolumn{2}{c}{ Failure } \\
& $P_{\mathrm{y}} / \mathrm{kN}$ & $\Delta_{\mathrm{y}} / \mathrm{mm}$ & $P_{\max } / \mathrm{kN}$ & $\Delta_{\max } / \mathrm{mm}$ & $P_{\mathrm{u}} / \mathrm{kN}$ & 298.46 \\
\hline Positive & 238.49 & 32.15 & 351.72 & 87.93 & -136.27 \\
Negative & -243.52 & -31.39 & -356.12 & -86.55 & -304.95 & -133.92 \\
\hline
\end{tabular}

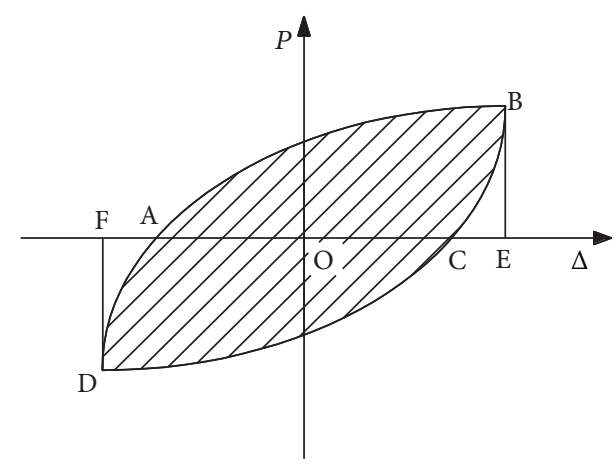

FIGURE 20: Hysteretic loop and energy dissipation capacity.

yields, and the skeleton curve gradually inclines toward the horizontal axis. The maximum base shear is $356 \mathrm{kN}$ at the ultimate stage. The bearing capacity then decreases to $298 \mathrm{kN}$ at failure owing to the serious damage of the core tube and frame.

3.5. Ductility and Energy Dissipation. The displacement ductility coefficient, $\mu$, is calculated by (4), and an equivalent viscous coefficient, $h_{\mathrm{e}}$, to evaluate the energy dissipation of specimen, is calculated by (5).

$$
\begin{aligned}
\mu & =\frac{\Delta_{\mathrm{u}}}{\Delta_{\mathrm{y}}} \\
h_{\mathrm{e}} & =\frac{1}{2 \pi} \cdot \frac{S_{(\triangle \mathrm{ABC}+\Delta \mathrm{CDA})}}{S_{(\triangle \mathrm{OBE}+\Delta \mathrm{ODF})}}
\end{aligned}
$$

where $\Delta_{\mathrm{u}}$ and $\Delta_{\mathrm{y}}$ are parameters as described in Table 5 , $S_{(\triangle \mathrm{ABC}+\triangle \mathrm{CDA})}$ is the area of one hysteretic loop as shown in Figure 20 , and $S_{(\triangle \mathrm{OBE}+\Delta \mathrm{ODF})}$ is the total area of $\triangle \mathrm{OBE}$ and $\triangle \mathrm{ODF}$.

The displacement ductility coefficient $\mu$ is 4.27. The equivalent viscous coefficient $h_{\mathrm{e}}$ is shown in Figure 21, and the maximum value is 0.374 when $\Delta_{9}$ reaches $88 \mathrm{~mm}$. It meets the requirement of $\mu \geq 3$ in Code for Seismic Design of Buildings (GB50011-2010). Compared with the results of other frames (L-shaped column composed of concrete-filled steel tubes frame [30]), the mentioned parameters are $\mu=3.31$ and $h_{\mathrm{e}}=0.336$. It is proved that specimen for CS frame-RC core tube building allows larger inelastic deformation.

3.6. Stiffness Degradation. The stiffness of specimen can be described by secant stiffness $K_{i}$, as calculated by

$$
K_{i}=\frac{\left|+P_{i}\right|+\left|-P_{i}\right|}{\left|+\Delta_{i}\right|+\left|-\Delta_{i}\right|}
$$

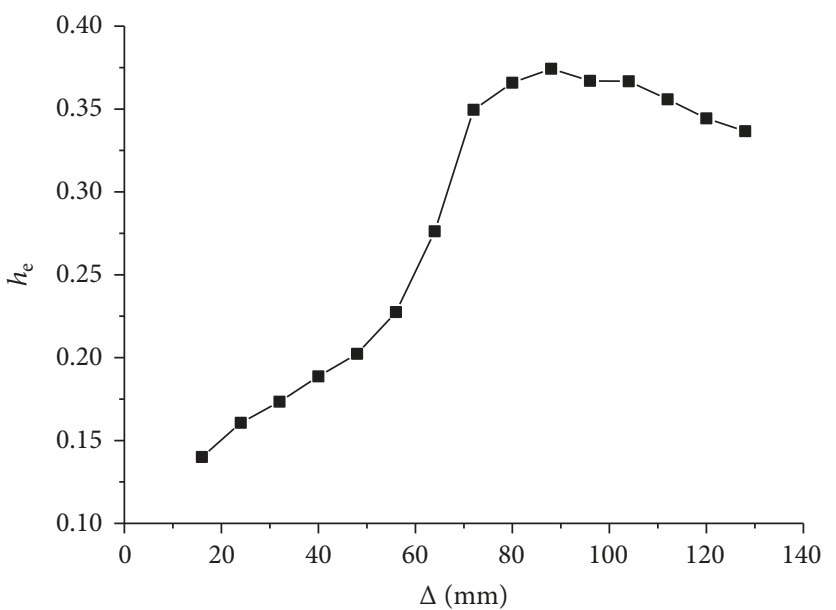

FIGURE 21: Energy dissipation capacity.

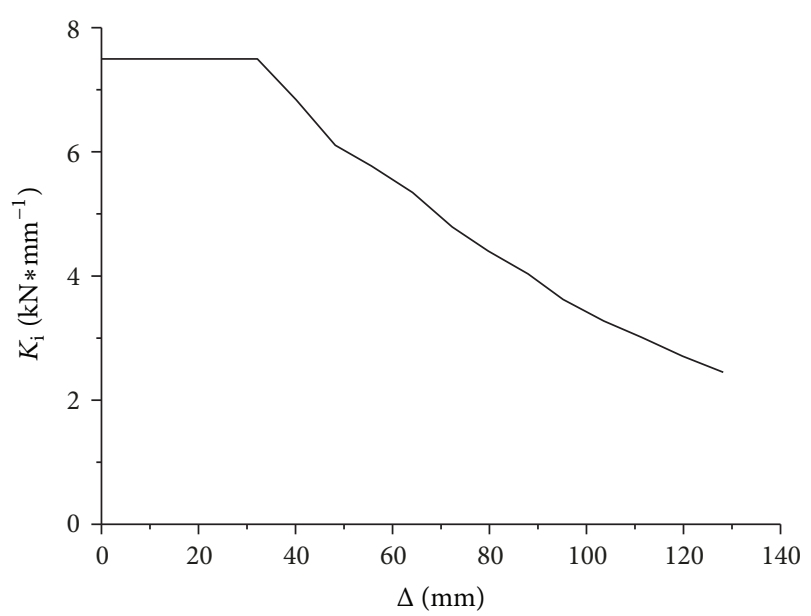

FIgURE 22: Degradation of stiffness.

where $P_{i}$ and $\Delta_{i}$ are the peak load and corresponding displacement at $i$-th displacement level of 9th floor, respectively.

The stiffness degradation is shown in Figure 22. It can be seen that the stiffness of the specimen remains constant in the initial stage, but it degenerates rapidly once the core tube damage. Platform segment shows the elastic stage of specimen, and the degradation reveals the cumulative damage of structure. Finally the stiffness degenerates for about $67.49 \%$. Compared with the result of [30], in which stiffness degradation is $79.07 \%$, CS frame-RC core tube buildings maintain larger stiffness even at failure stage. 


\section{Conclusions}

The seismic behavior of CS frame-RC core tube building was investigated, the damage process, crack pattern, and failure mode were observed, and the following was concluded.

(1) In the quasi-static test, the specimen failed mainly by the overturning mode. As the first seismic resistant system, the core tube carried the major load and suffered extensive damage. Major horizontal tension cracks and Xshaped oblique shear cracks occurred at the bottom of core tube. Once the core tube got damaged, the frame played the role of second seismic resistant system and continued to carry the surplus load. The joint experienced shear failure and the column experienced tensile failure, and the floor slabs failed in compression. The structure design satisfied the concept of "two seismic resistant systems."

(2) The hysteresis curve shape was between the spindle and the $S$ form, and the skeleton curve of the specimen was symmetrical in both positive and negative directions. The specimen generally exhibited yielding, ultimate, and failure stages. The specimen began to enter the plastic stage at top displacement $32 \mathrm{~mm}$. The structural maximum lateral bearing capacity was $356 \mathrm{kN}$ at $88 \mathrm{~mm}$ and failed at 132 $\mathrm{mm}$.

(3) The strain of steel skeleton in columns and concrete at the bottom of core tube exceeded $3000 \mu \varepsilon$. However strain of beams was generally less than $500 \mu \varepsilon$ and did not yield in the experiment. The frame design conformed to the seismic principles of "strong columns and weak beams" and "strong joints and weak members."

(4) The displacement ductility coefficient $\mu$ was 4.27 , which had met the requirement of $\mu \geq 3$ in Code for Seismic Design of Buildings. The equivalent viscous coefficient $h_{\mathrm{e}}$ was 0.374 , and the stiffness decreased by approximately $67.49 \%$ at failure stage. Compared with the result of similar structure, CS frame-RC core tube building allowed larger inelastic deformation, indicating the excellent seismic performance.

\section{Data Availability}

The data used to support the findings of this study are available from the corresponding author upon request.

\section{Conflicts of Interest}

The authors declare that there are no conflicts of interest regarding the publication of this paper.

\section{Acknowledgments}

This research was funded by Natural Science Foundation of Hubei Province of China (Grant no. 2016CFB604), Natural Science Foundation of China (Grant nos. 51108041 and 51378077), and Science Foundation of the Education Department of Hubei Province of China (Grant no. D20161305), and their support is gratefully acknowledged.

\section{References}

[1] J. Nie, M. Tao, Y. Huang, S. Tian, and G. Chen, "Research advances of steel-concrete composite structural systems," Journal of Building Materials and Structures, vol. 31, pp. 71-80, 2010.

[2] J.-W. Hu, Y.-S. Kang, D.-H. Choi, and T. Park, "Seismic design, performance, and behavior of composite-moment frames with steel beam-to-concrete filledtube column connections," International Journal of Steel Structures, vol. 10, no. 2, pp. 177-191, 2010.

[3] S. C. Goel, "United States-Japan cooperative earthquake engineering research program on composite and hybrid structures," Journal of Structural Engineering, vol. 130, no. 2, pp. 157-158, 2004.

[4] Y. Xiao, L. Zeng, Z. Cui, S. Jin, and Y. Chen, "Experimental and analytical performance evaluation of steel beam to concreteencased composite column with unsymmetrical steel section joints," Steel and Composite Structures, vol. 23, no. 1, pp. 17-29, 2017.

[5] L. Zeng, Y. Xiao, Y. Chen, S. Jin, W. Xie, and X. Li, "Seismic damage evaluation of concrete-encased steel frame-reinforced concrete core tube buildings based on dynamic characteristics," Applied Sciences (Switzerland), vol. 7, no. 4, 2017.

[6] S. Chen and P. Wu, "Analytical model for predicting axial compressive behavior of steel reinforced concrete column," Journal of Constructional Steel Research, vol. 128, pp. 649-660, 2017.

[7] Y. Y. Li and B. S. Yang, "Discussion on limit values of axial compression ratio of steel reinforced concrete columns," Applied Mechanics and Materials, vol. 578-579, pp. 37-40, 2014.

[8] M. Lin and K. Wang, "Seismic slope behavior in a large-scale shaking table model test," Engineering Geology, vol. 86, no. 2-3, pp. 118-133, 2006.

[9] X. Lu, Y. Zou, W. Lu, and B. Zhao, "Shaking table model test on Shanghai World Financial Center Tower," Earthquake Engineering \& Structural Dynamics, vol. 36, no. 4, pp. 439-457, 2007.

[10] J. B. M. Sousa Jr. and C. F. D. G. Muniz, "Analytical integration of cross section properties for numerical analysis of reinforced concrete, steel and composite frames," Engineering Structures, vol. 29, no. 4, pp. 618-625, 2007.

[11] X. Wang, "Study on ductility performance of T-shaped section steel reinforced concrete columns," Applied Mechanics and Materials, vol. 351-352, pp. 359-362, 2013.

[12] Z. Li, H. Qin, H. Dang, H. Li, and J.-S. Zhang, "Experimental study on mechanical property of steel reinforced concrete Lshaped short columns," International Journal of Modern Physics $B$, vol. 22, no. 31-32, pp. 5755-5761, 2009.

[13] J. Xue, L. Qi, L. Gao, and Z. Liu, "Mechanical behavior of lattice steel reinforced concrete inner frame with irregular section columns under cyclic reversed loading," Engineering Structures, vol. 128, pp. 225-236, 2016.

[14] B. Yuan, M. Zeng, and K. Ma, "Crack resistance capacity analysis of SRC column-RC beam node," Applied Mechanics and Materials, vol. 204-208, pp. 2994-3001, 2012.

[15] B. Wang, H. Jiang, and X. Lu, "Experimental and numerical investigations on seismic behavior of steel truss reinforced concrete core walls," Engineering Structures, vol. 140, pp. 164$176,2017$.

[16] L. Guoqiang, X. Zhou, and D. Xiang, "Shaking Table Study on a Model of Steel-Concrete Hybrid Structure Tall Buildings," Journal of Building Structures, vol. 22, no. 02, pp. 2-7, 2001. 
[17] M. Wu and X. Lü, "Shaking table model test and theoretical analysis for seismic resistance of hybrid structures," Earthquake Engineering and Engineering Vibration, vol. 24, no. 6, pp. 103108,2004

[18] G. Zhiguo, L. Xilin, L. Wensheng, L. Peizhen, Y. Song, and Z. Bin, "Shaking table model test of a hybrid high-rise building structure," Earthquake Engineering and Engineering Vibration, vol. 24, no. 4, pp. 99-105, 2004.

[19] X. Yantao, Design and experimental study on steel reinforced concrete frame-core wall structure with transfer floor, China Academy of Building Research, 2007.

[20] G. S. Kamaris, K. A. Skalomenos, G. D. Hatzigeorgiou, and D. E. Beskos, "Seismic damage estimation of in-plane regular steel/concrete composite moment resisting frames," Engineering Structures, vol. 115, pp. 67-77, 2016.

[21] E. Ellobody, B. Young, and D. Lam, "Eccentrically loaded concrete encased steel composite columns," Thin-Walled Structures, vol. 49, no. 1, pp. 53-65, 2011.

[22] Y. Yang, P. Wang, J. Wang, and X. Jin, "Seismic analysis of the hung curtain wall structure in Shanghai Center Tower," The Structural Design of Tall and Special Buildings, vol. 22, no. 11, pp. 847-861, 2013.

[23] N. Fanaie and S. Ezzatshoar, "Studying the seismic behavior of gate braced frames by incremental dynamic analysis (IDA)," Journal of Constructional Steel Research, vol. 99, pp. 111-120, 2014.

[24] E. Fereshtehnejad, M. Banazadeh, and A. Shafieezadeh, "System reliability-based seismic collapse assessment of steel moment frames using incremental dynamic analysis and Bayesian probability network," Engineering Structures, vol. 118, pp. 274-286, 2016.

[25] Z. Xu, P. Xu, and C. Xiao, "A study on the seismic performance of steel-reinforced concrete frame-concrete core wall high-rise mixed structure by large-scale shaking table tests and numerical simulations," Earthquake Engineering \& Structural Dynamics, vol. 42, no. 13, pp. 1951-1969, 2014.

[26] S.-S. Zheng, W. Yang, Q.-L. Tao, and Y. Hu, "Analysis of storey damage effect factors of SRC frame-RC core tube hybrid structure under cyclic loading," Applied Mechanics and Materials, vol. 166-169, pp. 52-55, 2012.

[27] P. Xu, Y. Xue, and C. Xiao, "Experimental Study on Seismic Performance of High-rise SRC Hybrid Structures," Building Structure, vol. 35, no. 5, pp. 3-8, 2005.

[28] Z. Lu, X. Chen, X. Lu, and Z. Yang, "Shaking table test and numerical simulation of an $\mathrm{RC}$ frame-core tube structure for earthquake-induced collapse," Earthquake Engineering \& Structural Dynamics, vol. 45, no. 9, pp. 1537-1556, 2016.

[29] S. Li, W. Zhao, and J. Jin, "The application of modesuperposition response spectrum method in seismic calculation of the boiler steel structure," Advanced Materials Research, vol. 594-597, pp. 1645-1651, 2012.

[30] T. Zhou, Y. Jia, M. Xu, X. Wang, and Z. Chen, “Experimental study on the seismic performance of L-shaped column composed of concrete-filled steel tubes frame structures," Journal of Constructional Steel Research, vol. 114, pp. 77-88, 2015. 


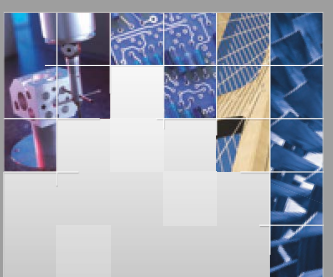

\section{Enfincering}
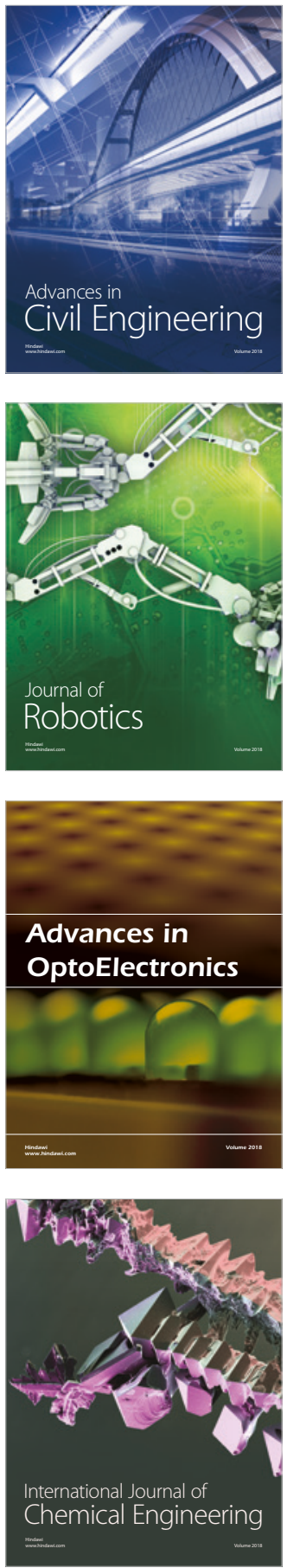

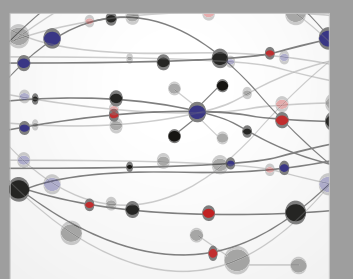

\section{Rotating \\ Machinery}

The Scientific World Journal

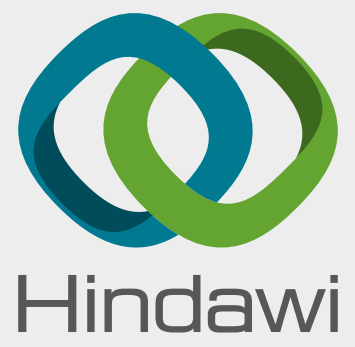

Submit your manuscripts at

www.hindawi.com
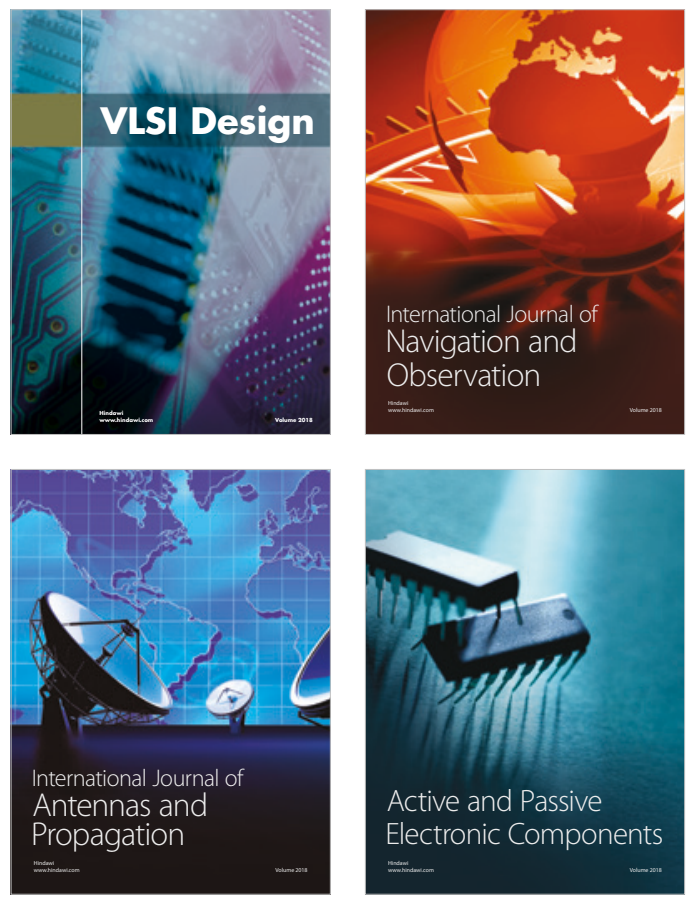
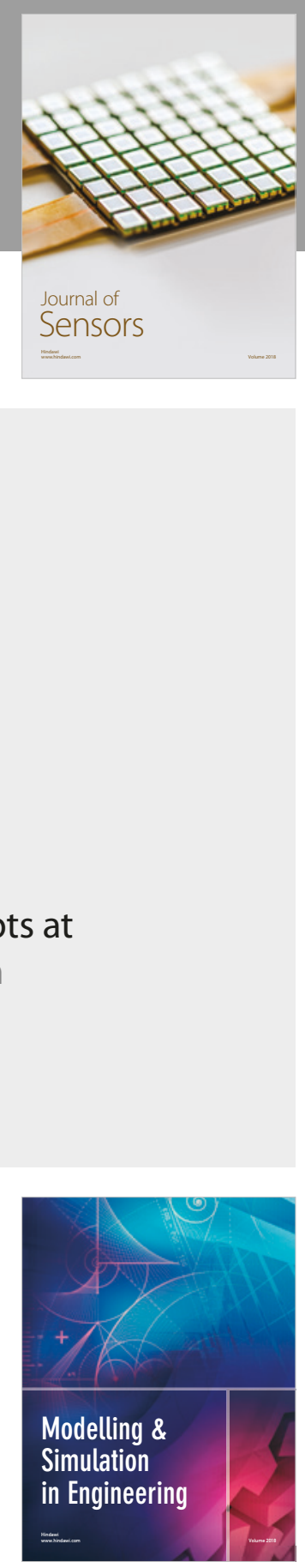

\section{Advances \\ Multimedia}
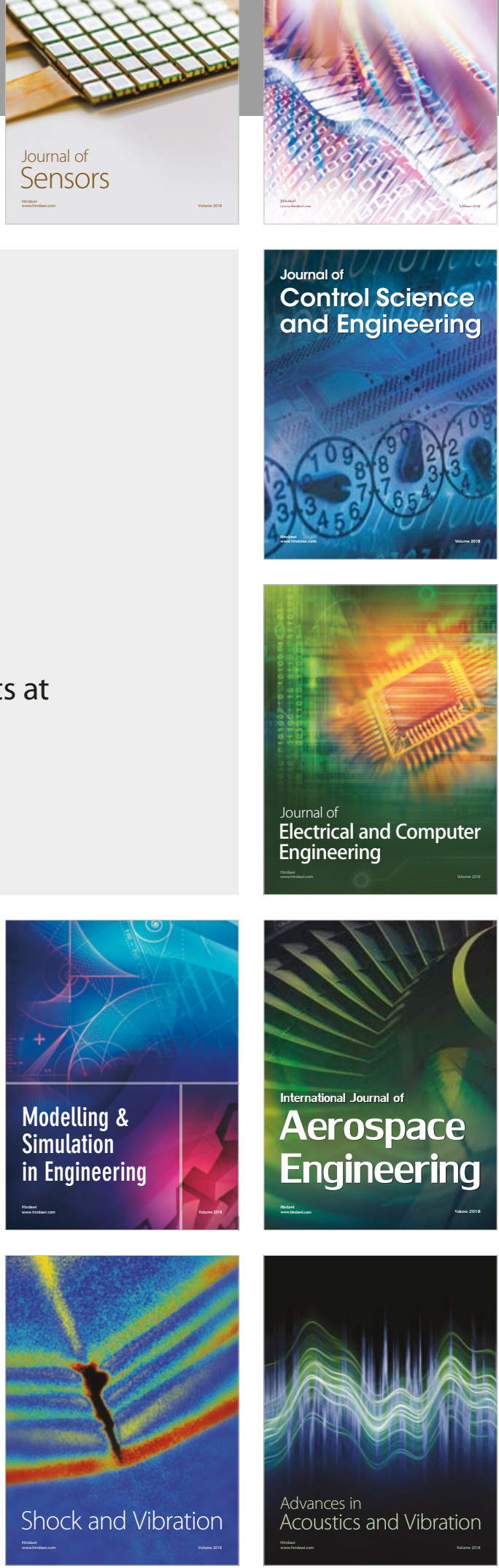